\title{
Details of canine hydrotherapy pools and treadmills in 22 hydrotherapy centres in the United Kingdom
}

\author{
McCormick $^{1}$, W. D., Oxley, J. A. ${ }^{2}$, Spencer, N. ${ }^{3}$ \\ ${ }^{1}$ Anglia Ruskin University, Cambridge Campus Sci 408, East Road, Cambridge, CB1 1PT \\ ${ }^{2}$ Independent Researcher, Measham, Swadlincote, DE12 7LQ \\ ${ }^{3}$ Moulton College, West Street, Moulton, Northamptonshire, NN3 7RR
}

Contact: wanda.mccormick@anglia.ac.uk

\section{Introduction}

Canine hydrotherapy has been noted to be beneficial for dogs with various neurological and orthopaedic conditions (e.g. paralysis, hip dysplasia), soft tissue injuries, as well as aiding in weight loss, and improving a dog's general fitness (Molyneuw 2004, Owen 2006, Monk 2007, Prankel 2008, Randall, 2010). The hydrotherapy industry has been noted to have increased dramatically over recent years (Waining and Others, 2011). Two of the most commonly found pieces of equipment within hydrotherapy centres are pools and underwater treadmills (referred to as 'treadmill' from this point forward), the latter of which has become increasingly popular (see Waining and Others, 2011). This is could be due to a treadmill being smaller in size, possibly less expensive in comparison to a pool facility which has been noted to require investment of circa $£ 35,000$ (Molyneux, 2004), or for some other reason. Despite the increased awareness and popularity there is still limited research on how hydrotherapy is best used when managing specific conditions (Kirkby and Others, 2012), and very little known about specifications of the equipment used and general practice management. This research aimed to explore features of the equipment currently in use within UK hydrotherapy centres in order to highlight any variations and identify the potential need for guidelines for hydrotherapy facilities.

\section{Method}

A questionnaire was distributed by email to the main contact of 146 Canine Hydrotherapy Association $(\mathrm{CHA})$ registered centres within the UK from $1^{\text {st }}$ April $-31^{\text {st }}$ May 2015. The questionnaire focused on the specifications of the hydrotherapy equipment alongside general practice management at centres (table 1). Spearman rank correlation coefficient was used to 
test the relationship between the length and width of pools and treadmills and were analysed using Minitab (version 16). A total of 22 questionnaires were received giving a $15.1 \%$ response rate.

Table 1. A list of areas which were covered in the questionnaire

\begin{tabular}{|c|c|c|}
\hline Pool \& Treadmill & Pool Specific & Treadmill Specific \\
\hline Equipment information & Equipment information & Equipment information \\
\hline - Size (length, width, depth) & - Pool above or below ground level & - Capable of inclination/declination \\
\hline - Temperature of water & - Pool has jets/jet settings & - Maximum depth of water \\
\hline & & - $\quad$ Speed settings \\
\hline General Practice & General Practice & General Practice \\
\hline $\begin{array}{l}\text { - Do staff go in the pool/treadmill } \\
\text { with } \operatorname{dog}(\mathrm{s}) \text { ? }\end{array}$ & $\begin{array}{l}\text { - Are multiple dogs allowed in the } \\
\text { pool? }\end{array}$ & $\begin{array}{l}\text { - Additional information on } \\
\text { encouraging dogs to enter }\end{array}$ \\
\hline - Method of dogs entering/exiting & $\begin{array}{l}\text { - Additional information on } \\
\text { encouraging dogs to enter }\end{array}$ & \\
\hline
\end{tabular}

\section{Results}

Of the 22 centres, 11 had only a pool, three only a treadmill and eight centres had both devices. Equipment varied greatly in size (table 2), but was generally rectangular in shape showing a significant correlation between the length and width of both the pools $(r=0.621, p=0.006)$ and treadmills $(\mathrm{r}=0.681, \mathrm{p}=0.043)$. The number of therapists per centre ranged from $1-6$ (mean: 1.68 ) with $63.6 \%$ having one, $18.2 \%$ two, $13.6 \%$ three and $4.5 \%$ had six therapists.

Table 2. Variation in measurements of hydrotherapy pools and treadmills.

\begin{tabular}{|l|c|c|c|c|c|c|c|}
\cline { 2 - 8 } \multicolumn{1}{c|}{} & \multicolumn{4}{c|}{ Pool (n=19) } & \multicolumn{2}{c|}{ Treadmill (n=11) } \\
\cline { 2 - 8 } \multicolumn{1}{c|}{} & Min & Max & Mean & SE & Range & Mean & SE \\
\hline Size & & & & & & & \\
\hline Length $(m)$ & 3.00 & 9.14 & 4.39 & 0.10 & $1.7-3.05$ & 2.17 & 0.05 \\
\hline Width $(m)$ & 1.50 & 4.60 & 2.41 & 0.04 & $0.58-1.0$ & 0.72 & 0.01 \\
\hline Depth / height $(m)$ & 1.20 & 2.50 & 1.32 & 0.02 & $0.75-1.3$ & 1.04 & 0.02 \\
\hline Volume $\left(m^{3}\right)$ & 5.4 & 74.38 & 16.72 & 1.01 & & & \\
\hline
\end{tabular}




\section{Hydrotherapy pools}

13 hydrotherapy pools were located above ground, three below ground and two were unknown. The temperature of the pool varied between $24-31{ }^{\circ} \mathrm{C}$, although the majority $(84 \%)$ were between $28-30^{\circ} \mathrm{C}$. All centres had therapists in the pool with the dogs during hydrotherapy sessions.

When asked how dogs get in and out of the hydrotherapy pool, all 19 pools had a ramp entry, 12 use manual handling (e.g. lifting) by the therapist(s) (one by the owner), eight use hoists and one stated steps into the pool. During hydrotherapy sessions, multiple restraint methods were used, according to individual dog requirements, these included, 18 using life jackets, 12 used 'Ruffwear' style harnesses, five used collars, three used long leads, two used buoyancy collars / head floats and one used no restraint in some settings. All except one centre had jets in the pool to create water current. All jets except one had different settings available; the centre whose jets didn't have different settings stated that they didn't use the jets.

To encourage a dog to enter the hydrotherapy pool at the start of sessions, ten centres found toys important, seven used treats, and seven felt the presence of the owner / therapist and the use of verbal encouragement was important.

\section{Treadmills}

The temperature of the water within the treadmills appeared to be consistent with that of the pools and varied between $24-30^{\circ} \mathrm{C}$, with the majority $(73 \%)$ being between $28-30^{\circ} \mathrm{C}$. The average depth of water in the treadmill was $65.85 \mathrm{~cm}$ (range: $56-83.8 \mathrm{~cm}$ ). The mean top speed of a treadmill was $151.40 \mathrm{~m} / \mathrm{min}$ (range: $99-241.5 \mathrm{~m} / \mathrm{min}$ ).

To encourage a dog into the treadmill the use of toys and treats were used by five out of the 11 centres. Again, owner presence and verbal encouragement to enter the treadmill were identified as important by two centres.

\section{Discussion}

The results of this research are important as they highlight the wide variation in hydrotherapy pools and treadmills. Further research could investigate the reason behind this variation (e.g. size of building, cost and availability) and aid in identifying what would be optimal for treating canine clients. In particular, there is sparse information on the way that dogs move within water, 
in fact, very few studies have been published assessing swimming gait in dogs and those that have often have small sample sizes (e.g., SICB, 2014). The authors are exploring this aspect of gait with a view to how hydrotherapy facilities can be established to allow for optimal aquatic movement.

The recorded temperature was consistent with published literature which states water is normally at a temperature of $30^{\circ} \mathrm{C}$ for dogs (Molyneux, 2004). However, the temperature reported to be used in human hydrotherapy has been noted to be in the region of $32-36^{\circ} \mathrm{C}$ (Bartels et al., 2007) and the focus on use in horses between 10-15 ${ }^{\circ} \mathrm{C}$ (King, 2016). Temperature can have direct effects on muscle relaxation and exercise (Intveld et al., 2010; Jurek and McCauley, 2009), as well as comfort levels of the dog, but the extent to how this can support training, exercise and rehabilitation in canine patients has not been fully explored. Another highly under-researched area is the use of jets to increase resistance, and therefore work (Cole and Becker, 2004), and this practice varies greatly between centres. Interestingly manual handling was noted to be used which could be problematic if a dog reacts, especially if injured, to entering water (Molyneux, 2004) and therefore the method of handling is an important factor.

In conclusion this small study raises a number of further questions about hydrotherapy equipment which point out the need for additional research from which relevant guidelines can be put in place. In particular, the impacts of facility dimensions on range of movement and temperature and current on rehabilitation success require further investigation to allow for appropriate centre design.

Acknowledgements: The authors would like to thank the Canine Hydrotherapy Association for helping with the distribution of the survey and advice on questionnaire drafts. The authors would also like to thank all centres who took part in the survey, and Claudia Wascher and the reviewers for their feedback on drafts of this paper.

\section{References}

BARTELS, E.M., LUND, H., HAGEN, K.B., DAGFINRUD, H., CHRISTENSEN, R. AND DANNESKIOLD-SAMSØE, B. (2007) Aquatic exercise for the treatment of knee and hip osteoarthritis. Cochrane Database Syst Rev, 4. 
COLE, A.J. \& BECKER, B. E. (2004) Comprehensive Aquatic Therapy. 2nd ed. Philadelphia: Elsevier.

INTVELD, E., COOPER, S. \& VAN KESSEL, G. (2010) The effect of aquatic physiotherapy on low back pain in pregnant women. International Journal of Aquatic Research \& Education. 4 (2), 147-152.

JUREK, C. \& MCCAULEY, L. (2009) Underwater treadmill therapy in veterinary practice. Veterinary Medicine. 104 (4), 182-190.

KING, M.R. (2016) Principles and application of hydrotherapy for equine athletes. Veterinary Clinics of North America: Equine Practice 32(1), 115-126.

KIRKBY, K. A., \& LEWIS, D. D. (2012) Canine hip dysplasia: reviewing the evidence for nonsurgical management. Veterinary Surgery, 41.

MOLYNEUX, J. (2004) Hydrotherapy pool-toy or tool? In Practice, 26(4), 226-228.

MONK, M. (2007) Hydrotherapy. (eds) McGowan, Goff, L. and Stubbs, N. In Animal Physiotherapy: Assessment, Treatment and Rehabilitation of Animals. 187-198.

OWEN, M. R. (2006) Rehabilitation therapies for musculoskeletal and spinal disease in small animal practice. GJCAP. 16 137-148.

PRANKEL, S. (2008) Hydrotherapy in practice. In Practice. 30272.

RANDALL, X. (2010) Principles and application of canine hydrotherapy. Veterinary Nursing Journal. 25; $23-25$.

SOCIETY FOR INTEGRATIVE AND COMPARATIVE BIOLOGY (SICB) (2014) How dogs do the 'dog paddle': An evolutionary look at swimming. Science Daily, 5 January 2014. Available at: www.sciencedaily.com/releases/2014/01/140105102502.htm [Accessed on 4/1/17]. 
WAINING, M., YOUNG, I. S., \& WILLIAMS, S. B. (2011). Evaluation of the status of canine hydrotherapy in the UK. Veterinary Record, 168, 407-407. 